\title{
Para pensar el humorismo con la risa de Castelao
}

\author{
Considering humor by way of Castelao's laughter
}

\author{
Juan CaAmaño \\ Queens College, City University of New York \\ Juan.Caamano@qc.cuny.edu \\ [recibido 06/09/2012, aceptado 11/02/2013]
}

\section{RESUMEN}

A través de un análisis selectivo de la obra de Alfonso Rodríguez Castelao, este artículo indaga en el problema del humorismo. La producción tanto gráfica como literaria del humorista nos permite comprender -frente a la más común evocación de los efectos positivos del humorismo en el arte y en la vida- que el humorismo es un asunto político e ideológico. Por eso no basta con mirarlo de modo crítico, sino que es necesario articular un humorismo distinto. El valor de la obra de Castelao reside precisamente en el hecho de auspiciar un arte del humor realmente alternativo, que serviría de aguijón para conocer mejor el mundo en que vivimos.

PALABRAS ClaVE: Castelao, humorismo, ideología, catarsis, dialéctica ser / no ser.

CAAmaño, J. (2013): "Para pensar el humorismo con la risa de Castelao", Madrygal (Madr.), 16: 13-22.

\section{RESUMO}

A través dunha análise selectiva da obra de Alfonso Rodríguez Castelao, este artigo indaga no problema do humorismo. A produción tanto gráfica como literaria do humorista permítenos comprender -fronte á máis común evocación dos efectos positivos do humorismo na arte e na vida- que o humorismo é un asunto político e ideolóxico. Por iso non basta con miralo de modo crítico, senón que é necesario articular un humorismo distinto. $\mathrm{O}$ valor da obra de Castelao reside precisamente no feito de auspiciar unha arte do humor realmente alternativa, que serviría de aguillón para coñecer mellor o mundo en que vivimos.

PALABRAS CHAVE: Castelao, humorismo, ideoloxía, catarse, dialéctica ser / non ser.

CaAmaño, J. (2013): "Para pensar o humorismo coa risa de Castelao", Madrygal (Madr.), 16: 13-22.

\begin{abstract}
By means of a selective analysis of Alfonso Rodríguez Castelao's work, this article examines the problem of humor. The humorist's graphic and literary work equally allow us to discern -in opposition to the commonplace view that sees only the positive effects of humor in both art and life- that humor is a matter of politics and ideology. For this reason, a critical stance towards humor is not enough; rather, a unique kind of humor is necessary. The value of Castelao's work resides precisely in the fact that it bears the prospect of a genuinely alternative humor, one that can serve as a stimulus to better understand the world in which we live.
\end{abstract}

KEY wORDS: Castelao, humor, ideology, catharsis, dialectic of to be / not to be.

CAAMAÑo, J. (2013): “Considering humor by way of Castelao's laughter”, Madrygal (Madr.), 16: 13-22.

SUMARIO: 1. Introducción. Sobre el sentido de humor. 2. Una lámina del álbum Nós. 3. Un ollo de vidro. 4. Láminas de Cousas da vida y una remembranza neoyorquina. 5. A modo de conclusión. 6. Referencias bibliográficas. 


\section{INTRODUCCIÓN. SOBRE EL SENTIDO DE HUMOR}

Resulta difícil imaginar un inventario de cosas que despiertan la risa. Probablemente sería infinito. Tampoco sabemos lo que sería el sentido del humor de los aztecas cuando se establecen en el valle de México hacia el siglo XII, o qué significaría reírse en la cuenca del Nilo en tiempos de los faraones (si bien nos hemos habituado a divertirnos con las momias en el cine o la televisión). Esto es, no sabemos lo que sería el humorismo si se formulara la pregunta fuera del marco habitual del universalismo antropológico. En todo caso, parece ser que el sentido del humor como alivio catártico se evoca ampliamente. Se extiende y por tanto se entiende, digamos, en nuestro mundo, más o menos, occidental $^{1}$. El funcionamiento de la catarsis supondría algo así como un aplacamiento de las inquietudes: siempre que se ríe es para sacarnos un peso de encima, algo que nos cuesta llevar sobre los hombros ${ }^{2}$. Dicho así, el humorismo tiene algo de tratamiento psiquiátrico en tanto que parece templar nuestras ansiedades y presiones cotidianas: un efecto terapéutico, al fin, que nos dice que en el fondo - o a la larga- todo está bien, que nuestro malestar no es tal o es superable.

El humor también nos puede decir que todo está mal. Y de ahí que aparezcan el sarcasmo, la burla y el escarnio. Sírvanos de ejemplo El Buscón de Francisco de Quevedo. Señalamos, de entrada, que el sentido del humor de El Buscón no es estrictamente de Quevedo sino que se alcanza, más bien, en una coyuntura histórica e ideológica específica. Desde este planteamiento básico se explican las risas de la narración de Quevedo como una suerte de respuesta, a partir de unas determinadas creencias sociales, a los valores del nuevo mundo mercantil forjado en los siglos XIV al XVI. Así, el humor mordaz de El Buscón va dirigido a las mudanzas y los "desequilibrios" sociales que este mismo mundo mercantil ha provocado -claro es, según el punto de mira feudalizante de la obra. La burla, lanzada desde dichas creencias y motivaciones -desde un consenso ideológico ya formado- está ahí para abrir fuego, digamos, contra el individuo que se atreve a vivir por cuenta propia, esto es, que renuncia a su situación social "orgánica". En este caso Pablos representa el individuo que renuncia a su "sangre" con esperanzas de subir a las cumbres de su sociedad. Conforme al metabolismo del orden feudal, cuyos motivos ideológicos gozan aún de vida prolongada en la época de Quevedo, la situación del individuo es eternamente un "lugar natural". El humorismo de El Buscón es por esto una descarga contra su protagonista y lo que este representa: por otra parte, las risas tienen el efecto colateral de negar el dolor, de truncar la posibilidad de que identifiquemos a Pablos con el sufrimiento, y por tanto el efecto de estorbar la denuncia. Al contrario, por razón de la burla se nos obliga a la complicidad. Sin duda, debería haber dolor en El Buscón pero solo hallamos risas ${ }^{3}$. Estas risas -su funcionamiento ideológico es obvio- callan el dolor de los pobres, de los que buscan la vida en el nuevo orden mercantil de la transición al capitalismo. Su funcionamiento está facilitado, asimismo, por el hecho de que para dicha perspectiva ideológica, el cuerpo de los pobres es un cuerpo que, como el de un esclavo o de un buey, está hecho para sufrir ${ }^{4}$.

Pensar el humor en términos de un uso "positivo", que se acercaría a un desahogo catártico, y otro "negativo" articulado por formas

${ }^{1}$ La identificación del humor con sus efectos salubres parece ser tan amplia como antigua: "[1]a creencia de que el humor es beneficioso para los humanos está documentada por la sabiduría popular en refranes y proverbios. Desde la Antigüedad hasta hoy día - pasando por Kant, Curzio Malaparte y Freud- muchos han depositado en la risa buena parte de la responsabilidad de la salud física y mental de las personas" (Iglesias Casal 2000: 440).

${ }^{2}$ Véase en esta línea el artículo de Sánchez Insúa (2007).

${ }^{3}$ En lo que se está trazando aquí en esquema respecto a El Buscón y de la ideología como consenso histórico, me hago eco de los planteamientos de Rodríguez (1994).

${ }^{4}$ Aludo al 'sustancialismo', la ideología que imbuye el funcionamiento de las sociedades feudales europeas y cuyos residuos y reverberaciones se sentirán en formaciones sociales posteriores al feudalismo. Para una extensa exposición del término, véase el texto clásico de Rodríguez (1974). 
como la sátira, el escarnio y el maldecir, entre otras, impide ver el problema de fondo que entraña el humorismo, problema que por otra parte sí se puede observar monda y nítidamente en lo que queda dicho sobre Quevedo: el de reírnos invariablemente desde nuestros prejuicios ideológicos. En este sentido, la obra del humorista Alfonso Rodríguez Castelao (Rianxo 1886 - Buenos Aires 1950) parece apuntar a un uso más despierto y responsable del humorismo ${ }^{5}$. La referencia al humorismo de Quevedo sirve aquí de puerta lateral para mostrar la relación del humor a sus condiciones de enunciación. No por eso creemos que el humor deja de existir como capacidad humana, sino que esta capacidad y su manifestación en el humorismo (en todas sus vertientes: desde el chiste alegre a la más virulenta sátira), independiente digamos del "género" de humor, está siempre encauzada por una ideología en un marco histórico determinado. $\mathrm{O}$ sea, hay que recordar que si la vida se vive a través del discurso (ideológico), el humorismo también es discurso. Son de este modo las estructuras sociales previas las que garantizan el sentido de humor, las que constituyen su lugar de enunciación. ¿En qué sentido se puede decir, pues, que tanto la obra gráfica como narrativa de Castelao se escapa a esto, a lo que parece ser ineludible? Lo veremos enseguida. Pero antes queremos precisar que este artículo está hecho a base de dejar de lado muchas cuestiones relacionadas con el humorismo de Castelao. Lo que nos interesa es únicamente poner de relieve lo que parece ser el criterio básico según el cual está amasada su obra humorística. Por este motivo, si no indagamos en los escritos teóricos sobre el humorismo del propio Castelao, salvo alguna escasa apuntación de su ensayo "Humorismo, dibuxo humorístico, caricatura" (recogido en Escolma posible) que nos parece decisi$\mathrm{va}$, es porque nuestro propósito es escrutar la práctica humorística del mismo (por encima de sus formulaciones, más o menos, conscientes) y particularmente cómo esta práctica destapa el consenso ideológico implícito en las situaciones varias que el humorista ha querido representar. En este sentido, partimos de la convicción de que la práctica humorística de Castelao se define por la aprehensión de lo contradictorio (en todos sus matices y en diversos contextos y escenarios) como un momento oportuno para efectuar una visión disidente respecto a ciertos valores, formas de pensar, creencias y prejuicios colectivos.

\section{UNA LÁMINA DEL ÁLBUM NÓS}

Quizás el dibujo que más nos agrada de la obra gráfica de Castelao sea uno que aparece en el álbum Nós (cuyos dibujos se realizan entre los años 1916 y 1918 para publicarse finalmente en 1931) ${ }^{6}$. Este dibujo se define mayormente por su oscuridad, por su sombra. Sobre todo nos fascina por ser un retrato despojado y agudamente paradójico, como también lo son diversas imágenes de su obra plástica y literaria; pero este es impecable en este sentido. Aquí aparecen dos figuras en penumbra con lo que parece ser el pórtico de una iglesia en el fondo. Entre sombras, una le susurra a la otra, "Na cadea dan de comer, pero teriamos que facer algún mal para irmos á cadea"7. Con esta imagen Castelao parece cumplir con la receta básica del humorismo formulada por el insigne escritor estadounidense Mark Twain, el nom de plume, como se sabe,

${ }^{5}$ La biografía de Castelao es notable tanto por su intensa actividad política como literaria. Fuera de Galicia y Argentina, la atención y curiosidad por la obra de Castelao, como parte del acervo artístico y literario hispánico, son bastante recientes, pero sirva a modo de orientación para neófitos la referencia a la "Introducción" de Alonso Montero (1982) y el artículo de López (1986). Por igual, se podrá consultar la bibliografía de y sobre Castelao que aparece en Cuatro obras, edición de Alonso Montero (1982).

${ }^{6}$ Una excelente selección de la obra gráfica de Castelao se reúne en la red. Véase por ejemplo: Castelao na rede (castelaonarede.wordpress.com), Colección Caixa Nova (www.coleccioncaixanova.com/autores 74 castelao.html), Museo de Pontevedra (www.museo.depo.es/coleccion/catalogo.castelao/e 03110000.html) y Ciudad de la pintura (http://pintura.aut.org/BU04?Autnum=13.863).

${ }^{7}$ Castelao na rede (castelaonarede.wordpress.com/castelao-artista/álbum-nos/\#jp-carousel-142; consulta 27/6/2012). 
de Samuel Langhorne Clemens, cuyo dictamen sirve de epígrafe a esa admirable obra de Castelao titulada Un ollo de vidro $(1920)^{8}$. Twain entiende que todo humor auténtico surge de un profundo dolor. Dicho así, el dolor y sufrimiento serían para Castelao ingredientes básicos para cualquier humorismo que merezca tal nombre, $\mathrm{y}$ con razón nos dice:

$[\mathrm{P}]$ arece que eu non son amigo de rir, e trabucado estará quen tal pense. Eu ben quixera que o meu ente rise con isa risa dos meniños, dos bos, dos sans e de dos felices; mais coma humorista galego, fondamente e sinceremente galego, teño que afogar as miñas risas diande dunha Verdade que chora. (1964b: 29)

Es decir, como humorista "fondamente e sinceramente galego" Castelao tiene que ahogar sus risas (las que corresponden a aquellos que, por una u otra razón, viven de espaldas al dolor), pero enterado "dunha Verdad que chora", se ve impulsado a imaginar otra risa, una que naciera de un humorismo auténtico. Podría parecer embarazoso pensar que hay un humor "auténtico", iluminado por el dolor y el malestar, y otro que no lo es. Y, de hecho, el humorismo es en sí tanto un problema (p. ej. no toda ironía, etc. promete ser sana o justa), como también un modo de encarar y comprender un problema. El humorismo podría, tácita o abiertamente, sancionar el dolor (y por tanto no ser auténtico) o, al contrario, puede (hacernos) reparar planamente en el dolor -incluso poner en duda la "moral" que nos obliga a consentirlo- hasta conmovernos a enjuiciarlo. Con esta formulación nos allegamos a la apuesta declarada de Castelao por un humorismo distinto: "O dibuxo humorístico debe ser outro e pra iso ha de furar os nosos sentidos e meténdose no mundo interior domeará os nosos sentimentos axeitándoos ó Ben; disa maneira será útil" (1964b: 28).

Esta actitud de humorista responsable no podría ser más obvia en el dibujo ya señalado: dos figuras conversan desde las sombras, en la oscuridad de la noche o de la vida; expresan su consternación a través de una dialéctica entre el "ser" y el "no ser", una dialéctica que nada tiene que ver con el ir y venir del indeciso Hamlet. Recordemos la inscripción: "Na cadea dan de comer." Se trata de dos figuras hambrientas y anónimas, sin rostro reconocible. Lo decisivo aquí es que el "ser" (potencial) de los protagonistas de este dibujo se invierte inmediatamente en el "no ser" porque de hecho no son, no se materializan, para el alimento o para aquellos que lo reparten. De ahí la otra clave para entender la ausencia del rostro, pues la falta de rostro no hace más que matizar su "no ser" para el hambre: aparentemente, a nadie le importa aquí el hambre, y el hambriento es, por eso, un nadie. Los protagonistas no son reconocidos en cuanto al hambre y de ahí que se desate lo absurdo e irracional: "teriamos que facer algún mal para irmos á cadea." Es decir, se puede "ser" en la cárcel (donde sí se puede comer) pero la cárcel es, ahí la ironía, imagen de la privación total. Lo absurdo es que las figuras del dibujo resulten invisibles en tanto que hambrientos, pero no en tanto que "criminales" (esto es, si se decidieran por cometer alguno delito). Indudablemente, la imagen de la cárcel nos remite a la Ley o al Estado, quien mientras por un lado se muestra interesado por ratificar el ser de cada persona (mediante el pasaporte, el DNI, etc.), por otro, respecto al hambre o al malestar, se desentiende. Pues mientras que hay que atentar contra la Ley para comer y ser reconocido (para que nos cuenten, como diría el filósofo francés Alain Badiou desde sus planteamientos, digamos, matemáticos) ¿cómo se puede seguir presumiendo la racionalidad de la ley y del poder? ${ }^{9}$ ¿No es éste el sentido -mostrar el sinsentido del sentido- del humorismo de Castelao? Es un humorismo, por cierto, que ya no permite risas cómplices, que ya no permite la cómoda identificación del sujeto con el chiste, la burla, la ironía o la sátira, sino que obliga ciertamente a un distanciamiento más objetivo e indagador, ya que detrás de la risa ligera que provoca el dibujo siempre está el dolor, un dolor que nos

\footnotetext{
${ }^{8}$ El epígrafe reza: "Debaixo do humorismo hai sempre unha grande door; por iso no ceo non hai humoristas" (Castelao 1964a). Todas las citas proceden de esta edición.

${ }^{9}$ Véase en este sentido la sugerente entrevista con Alain Badiou (2003).
} 
apura a efectuar una evaluación de las situaciones narradas y dibujadas. Si es cierto que la risa supone una avenencia con las razones de una determinada ideología, entonces sirve para acomodarnos mejor a las contradicciones sociales y para decirnos (engañosamente) que todo está bien. En Castelao otra risa es posible: la que resulta de una crisis de sentido. En lugar de ser válvula de escape, de caer en el desahogo catártico o el goce punitivo, el humorismo de Castelao es una manera de adentrarse en una realidad que nos compromete, una vez entendida, a juzgarla. Se trata de una crisis, porque tasadamente podemos derivar coherencia de una situación presentada como contradictoria, una situación que a la misma vez pasa a señalar los resquicios, los vacíos, en el discurso para permitirnos ver, efectivamente, el funcionamiento ideológico de este. Así se da en el dibujo de los hambrientos: en el juego siniestro de valores que efectúa el poder: "no ser" para el hambre y "ser" para la Ley, en fin, para la cárcel (que es, como decimos, la privación total).

\section{UN OLLO DE VIDRO}

Entre la narrativa de Castelao, quizás Un ollo de vidro: memorias de un esquelete (1920) concretice mejor que ningún otro texto toda esta lógica en la medida que desvela cómo ese sentido de la vida impuesto a las clases populares, protagonistas de la creación artística de Castelao, está asediado por paradojas y contrasentidos. Quizás por eso Un ollo de vidro, obra cuyos relatos representan las memorias de un esqueleto como indica el subtítulo, nos llame la atención por ser una obra de límites, y en especial una obra que se aprovecha del límite de la muerte como estrategia narrativa. La obra va precedida por una advertencia al lector en que se alude a este mismo límite como límite determinante:

Un día fitóume unha vaca. ¿Qué coidará de min?, pensei eu, e naquel intre a vaca baixou a testa e sigueu comendo na herba. Agora xa sei que a vaca somentes dixo: - Bo, total un home con anteollos. E ó millor eu non son mais que o que coidóu a vaca. Velahí a leidicia de pensar que cando a miña calivera estea ó descuberto xa non poderá xuzgarme unha vaca. (Castelao 1964a: 7-8)

Acaso esta vaca no sea más que signo de una norma de vida establecida en Galicia, pero también lo es el hombre de gafas que parece aceptar su juicio: "E o millor eu non son mais que o que coidóu a vaca". Y frente a esa norma de vida, la muerte podría ser una huida a través del límite: "xa non poderá xuzgarme unha vaca". Esto por lo menos debería ser, puesto que el mundo de los muertos, si es mundo, es el otro mundo. Pero las "Memorias" del esqueleto, compradas por el narrador a un enterrador, nos revelan una realidad asombrosamente familiar, una realidad que aparentemente desconoce fronteras.

Lo familiar, sin embargo, no deja de tener su cuota de extrañeza, por eso el asombro inicial: porque dichas memorias no fueron escritas cuando el esqueleto estaba en vida, como legado, sino en la ultratumba donde logró ver el mismo esqueleto cómo "vivían" los muertos. El legado, si se quiere, es de un muerto que cuenta lo que pasa en su mundo mortuorio a través de unas memorias como si la temporalidad fuese la misma a pesar de la frontera: como si hubiese que recordar lo que fue la muerte en tanto que experiencia en la sucesión temporal. Esta semejanza define el límite como uno entre dos mundos relacionados y por tanto equiparables. El ojo de cristal, que de nada le había servido en vida al esqueleto, ahora le sirve para ver con una claridad sorprendente. Lo que el lector logrará ver, a su vez, es que el Más Allá, con sus trabajos y sufrimientos, está ligado decisivamente al mundo de los vivos. Al borde de la muerte, estos - los vivos- se encuentran sin esperanza de cambiar su situación social y vital: "Nistes días hai moitos enterros. Non sei se haberá andacio, pois revolución non deba habela coa cobardía que teñen os vivos" (Castelao 1964a: 15). Por eso no es de extrañar que en las primeras memorias se nos diga que los esqueletos con los cuales se encuentra el protagonista se murieron de tristeza. Pero esa tristeza es debidamente lo que se quiere investigar, lo que se quiere someter a una inquisición, por decirlo así, desde los confines de la muerte y a través del ojo cristalino del esqueleto, un ojo que ve las cosas de otra manera. Se nos cuenta, por ejemplo, la historia de un zapatero con una voz honda y de calidad que aspiraba a ser cantante, pero como siempre desafina, lo echan del orfeón:

Deus regalárame cunha gorxa e non me dera orella...tan magoado fiquéi que perdín o coor e os folgos pró traballo, desganeime, enflaquecín e púxenme a morrer. Tódalas noites escoitaba os 
ensaios do orfeón acochadiño nas tebras da rúa sospirando arreo coa ialma doída. A tristura foi estruchándome a caixa do peito e no derradeiro ensayo do orfeón fuxeo a vida de min nun suspiro velaíño. O pobre zapateiro morréu de saudade. (Castelao 1964a: 16-17)

Tenemos, sin duda, la expresión literal del dolor psíquico en los términos "tristura" y en la "saudade" final. El zapatero quiere cantar y goza de talento para hacerlo ("en calidá de fenómeno entréi coma baixo no orfeón"), pero como no tiene oreja, no puede emplear su talento. $\mathrm{Su}$ garganta y su oreja son incompatibles. Esta incompatibilidad, llamémosle "personal" ("Deus regalárame cunha gorxa e non me dera orella"), no es de por sí problemática o irremediable sino en el momento en que el zapatero tiene que ajustarse al "principio de realidad", es decir, a los valores e imperativos reinantes, pues es el director del orfeón el que le dice que desafina y por eso los del orfeón "tiveron o callo de botarme fora" (Castelao 1964a: 16). Así esta incompatibilidad "personal" solo oculta la verdadera contradicción de base entre deseo y realidad que estructura esta historia del zapatero allende la tumba. Como decimos, esa contradicción de base se reduce a la tensión fundamental entre 'querer y no poder'. Es decir, el zapatero quiere (cantar), pero no puede (porque el director y los del orfeón se lo prohíben). Dicha tensión entre el deseo y la imposibilidad de realizarlo es el eje auténtico de la historia, porque es ahí donde se transparenta la relación, siempre omisa, del dolor físico o psíquico con el orden moral y social que lo engendra. Como sabemos, "O pobre zapateiro morréu de saudade", y aquí el término apunta a la soledad. En fin, a una soledad que representa la enajenación del zapatero de su propio deseo o ilusión. En efecto, la vida que le es dada solo le permite la oscuridad de la calle: "Tódalas noites escoitaba os ensaios do orfeón acochadiño nas tebras da rúa, sospirando arreo coa ialma doída". Sin duda, la risa está en lo estrambótico de la situación del zapatero, pues, es difícil tomar en serio su "ialma doída", puesto que si bien es una situación desafortunada, no debería suponer la muerte de nadie. Y, sin embargo, aquí sí. No se trata, claro está, de contraponer la reacción "extremada" del zapatero con la que hubiera sido la nuestra (más pragmática, racional, etc.) sino, al contrario, se trata de entender la historia en su propia estructura inmanente. De ahí que lo importante sea la contemplación de la exclusión que se padece y el imposible maridaje entre querer y poder.

La soledad se hace asimismo palpable en el cuento de la criada de servir. Esta nos dice que aunque no era bonita tenía juventud. El señor que la galantea le ofrece dinero para ir al dentista:

Un día caiume un dente e certo demo de señorito que andaba faguéndome as beiras, ofrecéume cartos pra que fose ó dentista. Mireime no espello e axiña comprendín canto me afeaba aquel portelo na boca, e tanto esgarabellóu o señorito na miña tolería que deixeime por o dente... ¡Ay! aquel dente custóume un fillo; aquel fillo custóume o creto e canto tiña de boa moza. Caín á rolos e atopeime coa morte, sen saber o que era un traxe de seda e nin un grolo de champán. Fea vivín, mallada e batida; agora podo durmir. (Castelao 1964a: 23-24)

Nuestra risa hacia lo absurdo e incoherente de esta situación -cambiar la juventud y la vida por un diente- se detiene al contemplar el espejo en que se mira la criada, el mismo espejo donde en seguida comprende ("axiña comprendín") cuánto la afeaba el hueco que tenía en la boca. Lo curioso de las citadas líneas es que 'mirar' (en el espejo) como 'comprender' (en la imaginación) resultan acciones vacías, puesto que lo que ocurre en la historia es que la criada no mira nada y no comprende nada y es por este motivo que cae en la trampa del señorito. Esto también se puede decir de otra manera: si la criada "comprende" cuánto la "afeaba aquel portelo na boca" y si le fue posible al señorito escarbar en su "tolería" es porque ambos "comprenden" y "miran" del mismo modo: o sea, la opinión del señorito ("certo demo de señorito" le llama la criada) y la imagen que devuelve el espejo (donde la criada "ve" y "comprende") radican en una misma "verdad" no dicha, en un consenso previo a lo dicho, visto y comprendido. Por eso decimos que la criada no mira ni comprende nada sino que participa de una predisposición a comprender (y creer) lo que le pide el señorito. Sabemos que no hace falta mucha insistencia por parte de éste, pues, esa "verdad" ya se comprueba en el espejo. Pero esa imagen especular con la que identifica la criada no es la suya. Esto es, ella no se identifica en el espejo sino 
que se identifica, es reflejada, en las ideas y los valores imperantes. Se juzga y condena ("axiña comprendín canto me afeaba aquel portelo na boca") según dichos valores e ideas que crean las condiciones propicias para el asentimiento de la criada ante los empeños del señorito por conquistarla. Su asentimiento le hará pagar muy caro el diente: nos dice que le costó un hijo, la honra y la preciada juventud. Sin duda, el espejo la desprecia, pero en él ve lo ajeno como propio y esto resulta una trampa mortal. Está claro que si se puede decir que 'vida' equivale a 'diente' -si este negocio es posible- es efectivamente porque los pobres llevan esos valores (ajenos) dentro como un cristal donde se miran pero no ven.

El único difunto de carne y hueso, que el esqueleto descubre en el Más Allá, es un vampiro. Descubierto una noche con los labios posados sobre el cuello de una niña de "cariña fraca $i$ encoveirada" (Castelao 1964a: 29), el vampiro de carne y hueso forma un contraste descomunal con los pobres huesos del esqueleto. Obviamente, el vampiro "vive" de la sangre de sus víctimas -sangre que le vale de elixir contra su transfiguración en huesos. Al venir en conocimiento de que en vida el vampiro fue un cacique, el esqueleto resuelve, sin más, tener que destruirlo. Para ejecutar su plan, el esqueleto acude a un amigo sesudo quien ofrece su opinión, digamos, contemporánea sobre el asunto: "Fuxiron os tempos en que o verdugo queimaba os cadavres sospeitosos de vampirismo e oxe non se permitiría en ningures espetar unha estaca no curazón dun cadavre" (Castelao 1964a: 30). La clave de todo esto es la posición alternativa que toma el esqueleto frente a la "sabiduría oficial" de su amigo; el esqueleto representa, sin duda, una posición forzosamente soterrada en tanto que amenazada por la concertada validez de las ideas de los de arriba: "O meu amigo, cheo de cencia oficial, moqueábase das xentes sinxelas que crên nos vampiros. Eu gardéi o meu segredo para non pasar por parvo e seguín preguntando solermiñamente" (Castelao 1964a: 30). Lleno de "cencia oficial", el amigo propone que la única manera de matar el vampiro es quemando el cadáver: es la única manera de separar el cuerpo astral del físico, según lo que el amigo había leído en los libros de teosofía. Pero hablar por una parte de un cuerpo astral, que es el que nutre al vampiro, y por otra de su cuerpo físico, no es solo un ocultismo insoportable para la razón popular del esqueleto, incapaz de imaginarse lo que podría ser un cuerpo astral, sino que es sobre todo un dualismo que su razón práctica popular descarta para llegar a una solución, digamos, más práctica ${ }^{10}$ :

Non quixen saber mais. Afasteime da miña biblioteca e fun pensando prós meus adentros: -Vampiros hainos; pois logo polo sí ou polo non, debían queimarse a tódolos caciques. Os caciques son capaces de facérense os mortos pra seguir vivindo á conta dos malapocados. (Castelao 1964a: 31-32)

Si por un lado el amigo estudioso no cree en los vampiros, es cierto que por otro recurre a lo que le dicen los libros ocultistas para advertir que la única manera de aniquilar a nuestro vampiro es quemándolo: las contradicciones estallan por todas partes. Para evitar las indecisas brumas de su amigo, el esqueleto se lleva por unos razonamientos, como decimos, prácticos que hacen pedazos todo dualismo de cariz oculto para así asimilar las nociones de vampirismo $\mathrm{y}$ caciquismo. O sea, no hay un cuerpo físico y otro astral, sino solo un cuerpo indivisible, el del cacique que posee todas las cualidades del vampiro, por lo cual se hace forzoso exterminarlo por completo. El límite de la muerte es, como se sabe, el límite del sentido, pero en $U n$

${ }^{10}$ Dicha actitud práctica de las clases populares tiene su inverso en la actitud de los que mandan, la cual Castelao sintetiza de manera admirable en la siguiente frase del álbum Nós: "-Ôs señoritos non lles gusta a choiva... - Pero gustanlle as patacas". Obviamente, los ricos o los que mandan desconocen el valor de la lluvia, pero no los labradores para quienes la lluvia está ligada a su actividad práctica. Así es la dudosa ciencia oficial (dislocada de su función práctica) del amigo quien, se presume, no ha sufrido la explotación de los caciques-vampiros. La frase de Castelao se cita en Garrido Couceiro (2001: 108). 
ollo de vidro traspasar ese límite, hacerlo poroso, se ha convertido en una estrategia narrativa formidable para conocer la sociedad en sus contrasentidos. Para hacer visible lo invisible -invisible, esto es, en tanto que el consenso sobre la verdad o la vida lo detenga.

\section{LÁMINAS DE COUSAS DA VIDA Y UNA REMEMBRANZA NEOYORQUINA}

Concluimos con dos imágenes reunidas en Cousas da vida solo para señalar la oposición de Castelao a un, llamémosle, "transcendentalismo" del humor (algo quizás que se parezca al cuerpo astral del vampiro), haciendo de él una cosa de la vida, esto es, localizándolo en la frontera del sentido y sinsentido del habla y del discurso ${ }^{11}$. Un ejemplo espléndido de todo lo que acabamos de esbozar se cristaliza en una imagen de Cousas da vida en la que dos hombres ironizan sobre la realidad económica: el primero dice: "Eu pensei que ían a repartir as riquezas", y el segundo objeta, "Pois eu xa me daba por satisfeito se repartisen a fame"12. El sarcasmo del primero descubre que no se observa el principio de la "justa" repartición de la riqueza, cosa que ha creado la diferencia entre ricos y pobres. Pero mientras que su enunciado reconoce desnudamente que lo que impera en cuanto a la distribución es siempre el embuste - decir una cosa y hacer otra- también soslaya la posibilidad de identificar las condiciones que producen la riqueza. Por eso el enunciado del hombre segundo, que desgaja incluso la mordacidad del primero, apunta a un desacierto en el enunciado del primero, puesto que su respuesta (la del segundo) implica que estamos a años luz de una repartición equitativa, porque el problema es mucho más fundamental (la frase "xa me daba por satisfeito" denota un posicionamiento más básico) y agudo: ¿cómo pensar en una justa distribución sin tener en cuenta las condiciones que la producen? Por eso hay que repartir el hambre, para paralizar las relaciones de explotación; hay que generalizar el hambre para saber cómo es posible el reparto de la riqueza, cómo se justifica (previamente) a través de las relaciones económicas desiguales, pues el hambriento es el que, en virtud de no tener nunca nada (de carecer de los medios para crear su propia vida), se encuentra siempre inerme frente al poder $y$, por tanto, frente a la explotación -de ahí la importancia de repartir el hambre. Pues, bajo la influencia ecualizadora del hambre (repartida justamente, como quiere el hombre segundo) nadie tiene más poder/valor que otro y, por ende, se estorban o imposibilitan las relaciones desiguales que legitiman el reparto desigual.

Hay otro dibujo de Cousas da vida que no podría ser más nítido en esta cuestión del sentido. En él aparecen tres viejas aldeanas. Una de ellas le dice a otra: "-Disque van subir os selos das cartas". La otra responde: "-iQué ben fixemos en non saber escribir!"13. Esto resulta ser otro ejemplo magnífico del humorismo de Castelao que se esfuerza por abrir un resquicio en el discurso para mostrarlo como tal discurso (y no como una forma de vida "natural"), pues solo podría ser un sinsentido que suba el precio de los sellos para quienes por exceso de pobreza son descontados de toda valorización económica o escolar. Volvamos a la dialéctica ser / no ser: ¿cómo van a ser para el precio estas mujeres que ni siquiera lo son para todo el engarce social en el que están inscritos los sellos, el precio y la escolarización que les enseñaría a escribir? Por cierto, los pobres no tienen su propia valorización de las cosas (no hay más valorización que la de los de arriba), pero viven sus vidas tan en desfase con los imperativos, 1lamémosle "normales", de su sociedad que destapar esta realidad con la respuesta irónica " $i Q u e ́$ ben fixemos en non saber escribir!" resulta un efecto humorístico brillante. No menos brillante es un apunte de Castelao que aparece en uno de sus cuadernos recordando su experiencia neoyorquina:

\footnotetext{
${ }^{11}$ Como indica Alonso Montero, esta colección reúne dibujos realizados para periódicos y revistas de Galicia antes de 1936. Cousas da vida surgió en diversos tomos publicados en los años 61, 62 y 71 por la editorial Galaxia en Vigo (1982: 35).

${ }^{12}$ Cousas da vida (usuarios.multimania.es/castelao2/files/cousas.htm; consulta 27/7/2012).

13 Ibid.
} 
Agora lémbrome da importancia que teñen as Sociedás protectoras de animales. En New York abonda que un gato atravese a Quinta Avenida para que se pare o tráfico. Non ocurre outro tanto cando pasa un home, porque... porque non hai Sociedás protectoras de homes. (2000: 583)

Efectivamente, estas líneas requieren poca explicación porque la contradicción (entre el parecer y el ser: o sea, entre lo que las cosas parecen ser y cómo realmente son) es tan filosa que el sentido que podría surtir de las llamadas sociedades protectoras de animales estalla inmediatamente en mil pedazos. Por un lado, se muestra lo que parece ser: el amor y los cuidados que supone una sociedad protectora (la de los animales, digamos, pero advirtiendo la metáfora no sería desacertado pensar en una sociedad protectora a secas). Por otro, se muestra lo que realmente es: entre los hombres no hay protección solo hay atropellos. El problema no es que se traten mejor a los animales que a los hombres, sino, al contrario, que a los hombres no se les trata con el mismo amor y cuidados que se alegan dar a los animales. Pues, si, como dice Castelao, no hay sociedades protectoras de hombres va comprendido que no hay sociedad que valga. En fin, es un chiste que despierta en nosotros una risa que confiesa el sinsentido del cual está hecho el sentido (de nuestras vidas).

\section{A MODO DE CONCLUSIÓN}

Los comentarios y las explicaciones que venimos realizando de la obra de Castelao se cimentan en la hipótesis básica de que su humorismo tiene como asiento y núcleo esencial la contradicción; se trata, pues, de un humorismo viable solo en la articulación y puesta en escena de cotidianos sinsentidos con el fin de incitar a espectadores y lectores a opinar sobre las ideas que Castelao ha elegido narrar y dibujar. El despliegue de contradicciones, en los ejemplos vistos y analizados, implica, pues, un humorismo que opera como una suerte de mirada alternativa: "O humorismo interpreta a vida dunha maneira sinxela e forte, non somente plástica senón ideolóxica" (Castelao 1964b: 30). Es una mirada ideológica - una mirada que procede con ideas- pero ideas incompatibles con las ideas responsables por el dolor representado en la obra de Castelao. Por esa razón es cierto que, como una interrogación sobre el "sentido" que descubre sus desbarros, el humorismo de Castelao supone una inestimable oportunidad para asimismo interrogarnos sobre la vida que tenemos (¿con qué hacemos comunión al reír?). Quizás por eso no deberíamos olvidarnos nunca del humorismo de Castelao.

\section{REFERENCIAS BIBLIOGRÁFICAS}

Alonso Montero, Xesús (1982): “Introducción”, en Cuatro obras (Teatro, relatos, fantasía macabra, ensayos) de Alfonso R. Castelao. Madrid: Cátedra.

BAdIou, Alain (2003): "Beyond Formalisation: An Interview" (entrevista realizada por Peter Hallward), Journal of the Theoretical Humanities 8/2, pp. 111-136.

Castelao, Alfonso R. (2000): Obras (coord. H. Monteagudo), vol. 3. Vigo: Galaxia. (1982): Cuatro obras (Teatro, relatos, fantasía macabra, ensayos) de Alfonso R. Castelao (ed. X. Alonso Montero). Madrid: Cátedra. (1964a): Un ollo de vidro: Memorias de un esquelete. Vigo: Galaxia. (1964b): Escolma posible (prólogo y selección de Marino Dónega). Vigo: Galaxia. (1962): Cousas da vida. Vigo: Galaxia, 2 vols.

Castelao na rede: castelaonarede.wordpress.com (consulta 27/7/2012).

Ciudad de la pintura: http://pintura.aut.org/BU04?Autnum=13.863 (consulta 24/1/2013).

Cousas da vida: usuarios.multimania.es/castelao2/files/cousas.htm (consulta 27/7/2012).

Garrido Couceiro, Xoán Carlos (2001): O pensamento de Castelao. Vigo: Edicións A Nosa Terra.

IgLESIAS CASAL, Isabel (2000): "Sobre la anatomía de lo cómico: recursos lingüísticos y extralingüísticos del humor verbal", en $\mathrm{M}^{\mathrm{a}}$ Antonia Martín Zorraquino / Cristina Díez Pelegrín (edas.), ¿Qué español enseñar? : norma y variación lingüisticas en la enseñanza del español a extranjeros. 
Actas del XI Congreso Internacional ASELE (Zaragoza, 13-16 septiembre 2000). Zaragoza: Universidad, pp. 439-449.

López, Siro (1986): “Castelao, humorista”, Anthropos 65, pp. 41-45.

Museo de Pontevedra: www.museo.depo.es/coleccion/catalogo.castelao/e03110000.html (consulta 27/7/2012).

Rodríguez, Juan Carlos (1974): Teoría e historia de la producción ideológica. Madrid: Akal. (1994): La literatura del pobre. Granada: Comares.

SÁnchez InsúA, Alberto (2007): "Freud y Bergson. El chiste y la risa y su relación con lo social", Arbor. Ciencia, pensamiento y cultura CLXXXIII/723, pp. 103-121. 